\title{
NUMERICAL SIMULATION OF HOLLOW AND CONCRETE-FILLED STEEL COLUMNS
}

\author{
Shengbin $\mathrm{Gao}^{1}$ and Hanbin $\mathrm{Ge}^{2, *}$ \\ ${ }^{1}$ Associate Professor, Department of Civil Engineering, \\ Shanghai Jiao Tong University, Shanghai 200240, China \\ ${ }^{2}$ Associate Professor, Department of Civil Engineering, \\ Nagoya University, Nagoya 464-8603, Japan \\ *(Corresponding author: E-mail: ge@civil.nagoya-u.ac.jp)
}

Received: 5 September 2006; Revised: 30 March 2007; Accepted: 4 April 2007

\begin{abstract}
This paper aims to predict the inelastic behavior of thin-walled steel and composite structures, such as hollow and concrete-filled steel columns. For this purpose, a three-dimensional (3D) elasto-plastic finite element analysis methodology has been presented for both thin-walled steel columns with pipe and box-shaped sections, and concrete-filled steel box columns. By comparing with experimental result, it is concluded that the proposed analytical method can give an accurate prediction to the experimental results of both steel and composite structures.
\end{abstract}

Keywords: Steel column; concrete-filled steel column; interface element; cyclic loading; elasto-plastic behavior; buckling mode

\section{INTRODUCTION}

Cantilever steel hollow and concrete-filled columns (CFT) have been widely designed and used as bridge piers in many countries. Such cantilever type bridge piers occupy less space and thus allow the free traffic flow in the roads below the highways. Moreover, concrete-filled steel columns can provide excellent seismic resistant behavior, such as high strength, high ductility, and large energy absorption capacity. As a result, various researches on these types of structures have been conducted in recent years (Gao et al. [1]; Ge and Usami [2, 3]; Ge et al. [4, 5]; Morino [6]; Schneider [7]; Susantha et al. $[8,9] ; \mathrm{Hu}$ et al. [10]). Figure 1 shows a view of steel box-section bridge pier damaged during Hyogoken-nanbu earthquake near Kobe city in Japan on January 17, 1995.

A clear understanding of inelastic behavior is very important in developing a seismic design methodology for these structures. To this end, the load-displacement curves of the structures play a

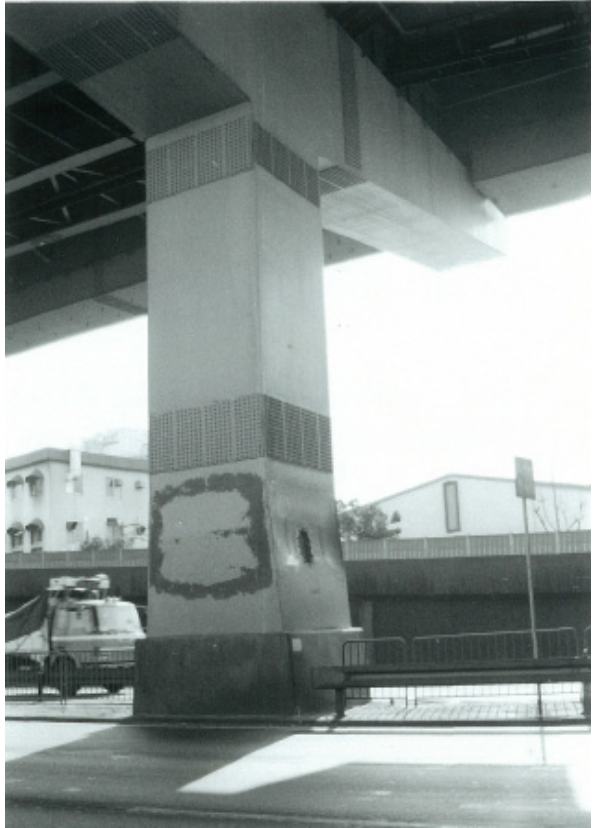

Figure 1. Steel Box Section Bridge Pier Damaged During Hyogoken-nanbu Earthquake Near Kobe City in Japan on January 17, 1995 very important role. To date, fiber model analysis is usually considered as an effective and convenient approach for capacity prediction of structures (Susantha et al. [8, 9]). However, this concept without considering local buckling of steel members or interaction between steel-concrete interfaces of composite members needs an additional criterion to determine the ultimate state. On the other hand, three dimensional approaches are very limited because of time-consuming of such analyses and complicated modeling in the case of composite structures. As the rapid development of computers and the spread of use of structural analysis software packages, the 3D analysis will be widely used to better understand inelastic behavior of complicated structures. 


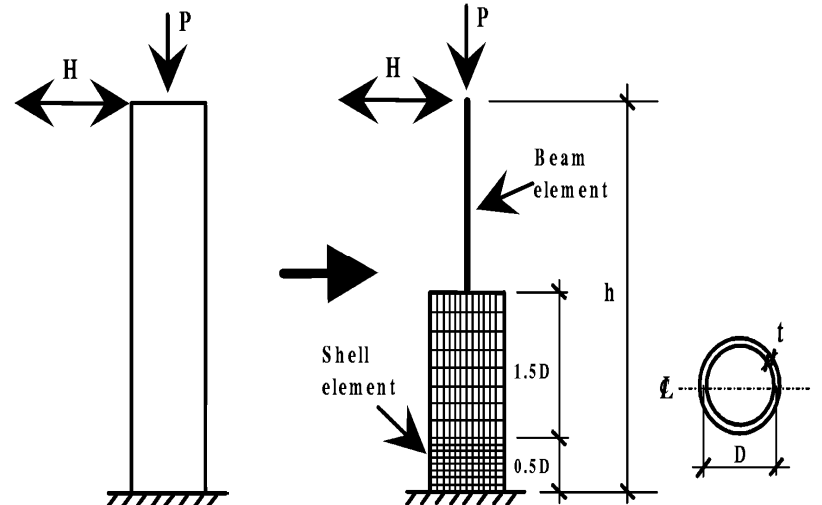

(a) Pipe Section Column (Pl)

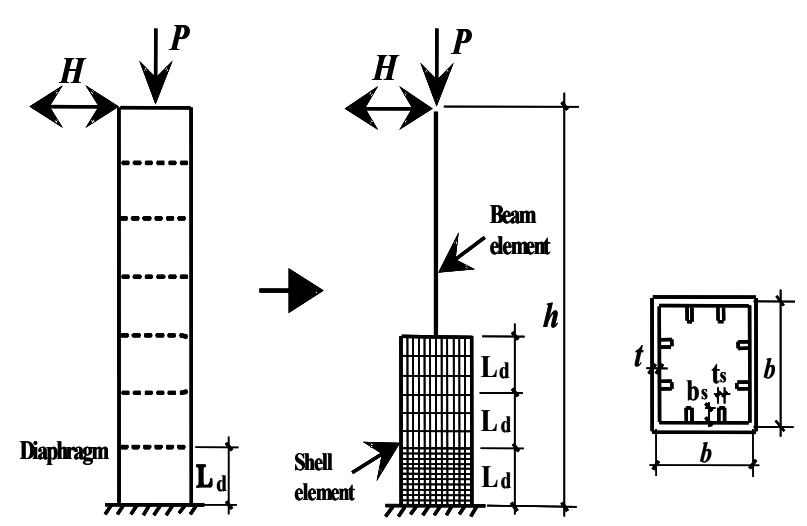

(b) Box Section Column (KD-5)

Figure 2. Analytical Models of Steel Columns

This paper presents a three-dimensional finite element analysis methodology for determining the load-displacement relation of steel and composite structures under either monotonic or cyclic loading. For this purpose, a software package DIANA [11] is employed. The structures analyzed are hollow steel columns with pipe and box sections, as well as concrete-filled steel box columns. The results of the analysis are compared with those of the experiments. It is found that the presented analysis methodology can give an accurate prediction to the experimental results in cases of both steel and concrete-filled steel box columns.

\section{CYCLIC BEHAVIOR OF HOLLOW STEEL COLUMNS}

\subsection{Analytical Model}

Two kinds of steel columns (Nakamura et al. [12]; Nishikawa et al. [13]), as shown in Figure 2 are adopted in this analysis. For thin-walled steel columns of uniform pipe-sections and box-sections subjected to constant axial load and cyclic lateral displacement, local buckling generally occurs near the base of the columns. Therefore, shell elements that can consider local buckling are employed for the lower part of the column. The upper part of the column is modeled using beam-column elements. For the beam-column elements, the spread of plasticity is accounted for both through the cross-section and along the member length. The element type is 3-node open section beam element (CL18B).

For the shell elements, the spread of plasticity is considered through the thickness and the plane of the element. The element type is a four-node curved shell element (Q20SH) that has four integration points within the plane and five integration points across the thickness.

Half of the column is modeled due to the symmetry of both geometry and loading. With respect to the mesh division of column P1, the length from the base which equals to the radius of the column is divided into 15 segments, while the following length of 3 times of the radius is only subdivided into 10 segments along the column length. In the circumferential direction, both are divided into 16 segments. For the beam-column elements, it is divided into 10 segments. Therefore, the analytical model of column P1 consists of 400 shell elements and 10 beam-column elements. In addition, a stiff plate with infinite bending stiffness is assumed in the interface between the beam-column elements and shell elements. A similar mesh division method is applied to the steel box-sectional column KD-5. It is noted here that the longitudinal stiffener should be divided into more than 3 meshes in width direction in order to consider its buckling behavior. 
The modified Newton iteration technique coupled with the displacement control method is used in the analysis. The energy convergence criterion is adopted in the analysis and the convergence tolerance is taken as $10^{-5}$. The initial geometrical deflections and residual stresses are not taken into consideration.

\subsection{Geometrical and Material Properties}

The tested specimen $\mathrm{P} 1$ has a slenderness ratio parameter of $\bar{\lambda}=0.26$ and radius-thickness ratio parameter of $R_{t}=0.11$ (Nishikawa et al. [13]; Gao et al. [1]). The main dimensions and material properties are: $h=$ column height $=3403 \mathrm{~mm} ; r=$ radius of gyration of cross section $=315 \mathrm{~mm}$; $\sigma_{y}=$ yield stress $=289.6 \mathrm{MPa} ; E=$ Young's modulus $=206 \mathrm{GPa} ; v=$ Poisson's ratio $=0.3 ; D=$ diameter of the column $=891 \mathrm{~mm}$; and $t=$ thickness $=9 \mathrm{~mm}$. During the test, the column is subjected to a constant axial load of $P / P_{y}=0.12$ and cyclic horizontal displacement at the tip. Here, $P_{y}$ denotes the squash load.

The tested specimen KD-5 has a flange plate width-thickness ratio parameter of $R_{f}=0.45$ and column slenderness ratio parameter of $\bar{\lambda}=0.30$ (Nakamura et al. [12]; Ge et al. [5]). The dimensions of column KD-5 are: $h=3303 \mathrm{~mm}$; flange and web width $b=738 \mathrm{~mm}$; flange and web thickness $t=12 \mathrm{~mm}$; stiffener width $b_{s}=90 \mathrm{~mm}$; stiffener thickness $t_{s}=9 \mathrm{~mm}$. The material properties are: $\sigma_{v}=350.2 \mathrm{MPa} ; E=206 \mathrm{GPa} ; v=0.3$. Moreover, $P / P_{y}=0.166$.

The kinematic hardening constitutive model is employed in this analysis. The hardening rates of the employed bi-linear stress-strain relation are assumed as $E^{\prime} / E=1 / 100$, which approximately equals to the slope of the line joining the initial yield point to the loading point corresponding to $5 \%$ axial strain.

\subsection{Comparison of Hysteretic Curves}

The curves of nondimensionalized horizontal load, $H / H_{y}$, versus horizontal displacement, $\delta / \delta_{y}$, from both the experiment and analysis are shown in Figure 3. The notations, $H_{y}$ and $\delta_{y}$, represent

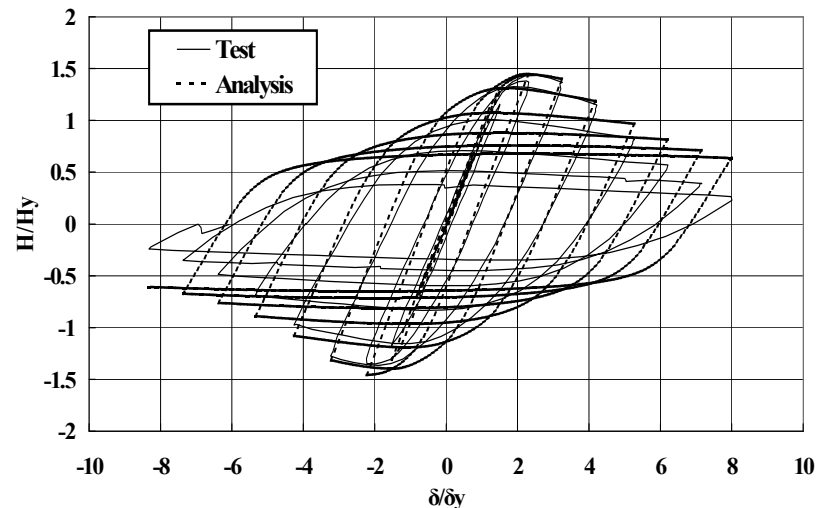

(a) Pipe Section Column (Pl)

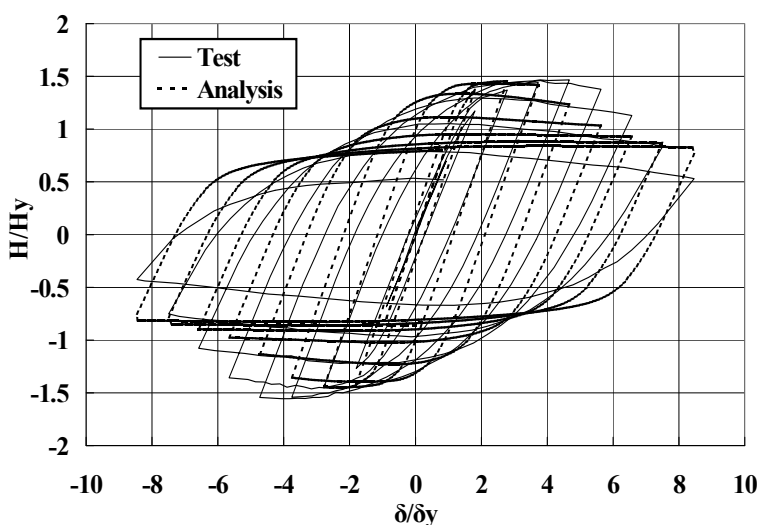

(b) Box Section Column (KD-5)

Figure 3. Comparison of Load - Displacement Relation of Steel Columns respectively the yield load and yield displacement considering the effect of axial load (Gao et al. $[1])$. 


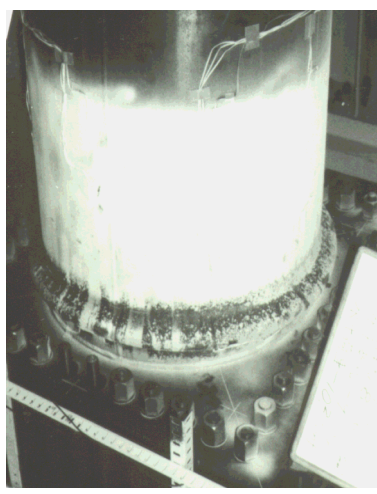

Experiment

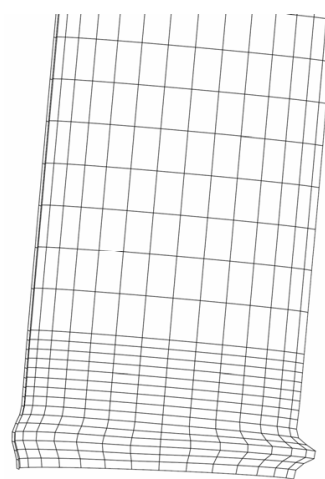

Analysis

(a) Pipe section Column (Pl)

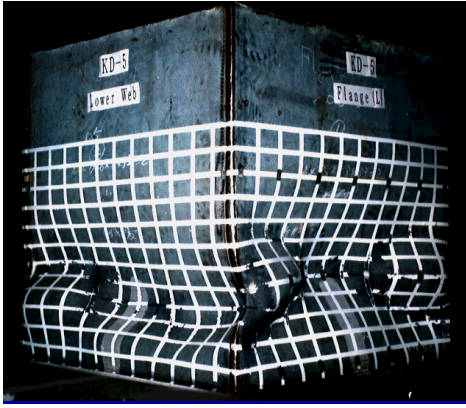

Experiment

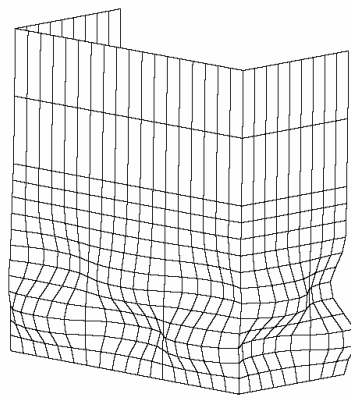

Analysis

Figure 4. Comparisons of Buckling Modes of Steel Columns

Figure 3(a) shows the comparison of hysteretic curves between the present analysis and the experimental result of column P1. It is observed that the shape of the hysteretic loops and the ultimate strength obtained from the present analysis is in good agreement with the experimental result. Comparison of hysteretic curves of the column KD-5 is shown in Figure 3(b). The ultimate strength of the present analysis coincides well with the experiment although the post-buckling strength of the analysis is a little lower than the experiment. This indicates that the developed FEM formulation can accurately predict the cyclic behavior of such steel structures.

\subsection{Comparison of Local Buckling Modes}

Figure 4 shows the local buckling modes obtained from both the experiment and analysis, respectively. It is observed that the buckling mode of either the column P1 or column KD-5 is almost the same as that of the corresponding test specimen. The part near the base of the pipe column P1 bulged outward and a half sine-wave is formed, while in the box column KD-5, the outward and inward buckling mode for both flange and web plates similar to that of the experiment is well simulated.

\section{PURE COMPRESSION BEHAVIOR OF CONCRETE-FILLED STEEL COLUMN}

\subsection{Analytical Model}

The analytical model shown in Figure 5 is a concrete-filled thin-walled steel stub-column of box shape (Ge and Usami [2]). Due to its symmetry, one-eighth of the column is taken for the analysis. The mesh division is shown in Figure $5(\mathrm{~b}) .8 \times 8$ meshes are employed across the cross section and 10 divisions are made along the axial direction. In the analytical model, eight-node linear solid element is employed to model concrete part. Four-node isoparametric shell element is used for steel plate panel. The position of the shell element is set at the center line of the steel plate panel.

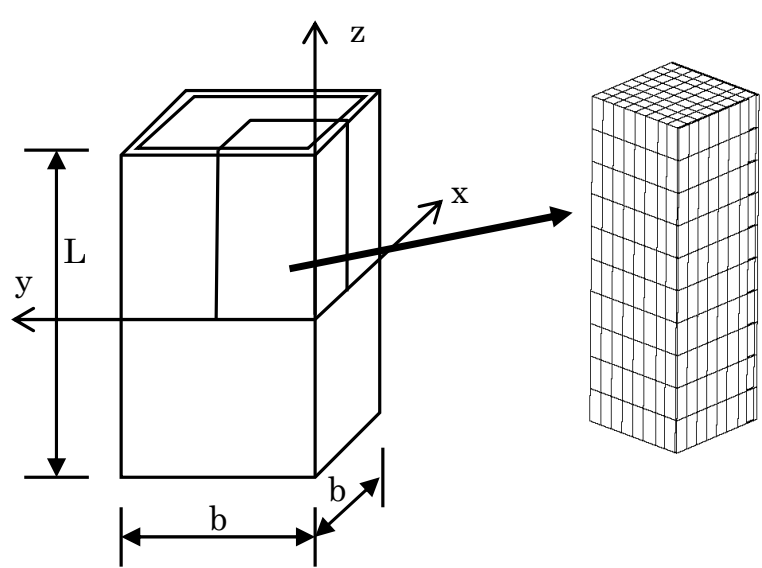

(a) Specimen U12-C

(b) Mesh Division

Figure 5. Analytical Model of Concrete-filled Steel Column under Pure Compression 


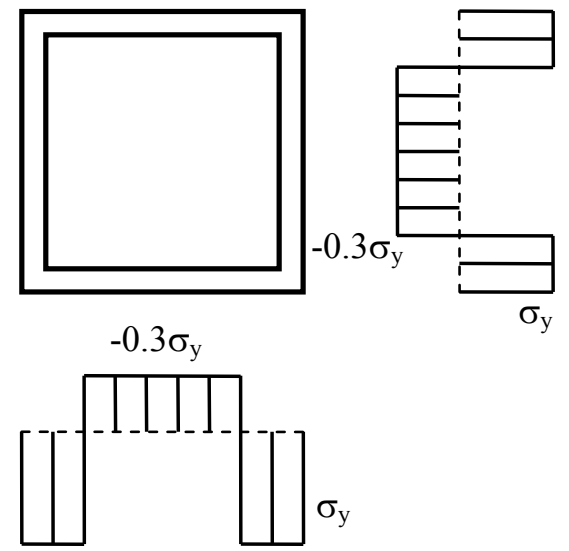

Figure 6. Distribution of Residual Stresses of Specimen U12-C due to Welding

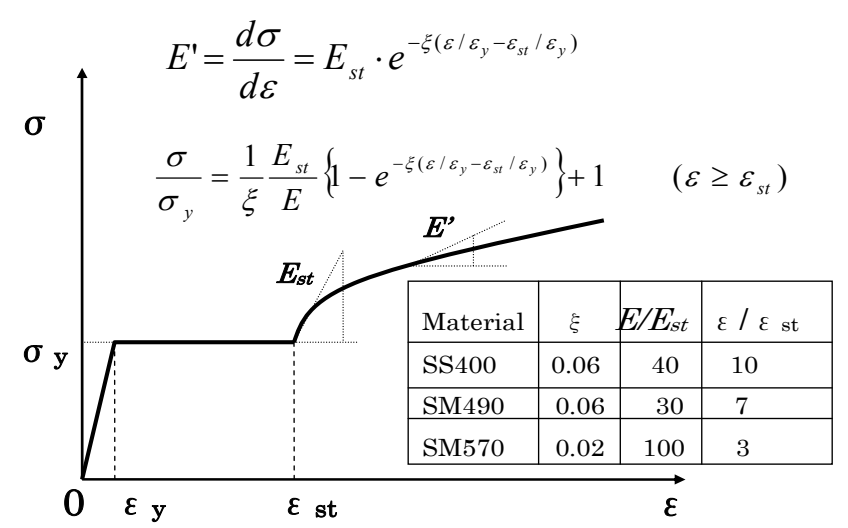

Figure 7. Uniaxial Stress-strain Relation for Steel

Plane interface element is used to model the interaction between steel and concrete. The plane interface element is an isoparametric element between two planes in a three-dimensional configuration, with which the interface surface and directions are evaluated automatically from the geometry of the element itself. In this analysis, the initial out-of-flatness is not taken into consideration due to its negligible effect on the ultimate strength (Ge and Usami [2]). An idealized form of residual stresses pattern of the plate panel due to welding is employed, as shown in Figure 6 (Chen and Ross [14]).

\subsection{Material Properties}

The von Mises yield criterion is adopted to consider the material property of the steel plate. As shown in Figure 7, strain hardening of the steel is taken into consideration (Usami and Ge [15]), 1998). A nonlinear elastic constitutive law of the interface element is employed to model the interaction behavior between the steel plate and the concrete. It is assumed here that the interface element behaves elastically in compressive regime, but it can not resist shear stresses as well as tensile stresses.

The Drucker-Prager type yield surface with 10 degree of friction angle is used for concrete. To investigate the effect of the lateral confinement on concrete, two types of uniaxial stress versus strain relations of concrete (i.e., unconfined and confined concrete) are employed. The uniaxial stress-strain relation of the unconfined concrete ("Concrete Standard Specification" [16]) is shown in Figure 8(a). Here, fc denotes the uniaxial strength and $\varepsilon_{c}$ is the corresponding strain of the unconfined concrete. When concrete is subjected to laterally confining pressure, both the uniaxial strength $\mathrm{f}_{\mathrm{cc}}$ and the corresponding strain $\varepsilon_{c c}$ will be larger than those of unconfined concrete. The relations between $\mathrm{f}_{\mathrm{cc}}, \mathrm{f}_{\mathrm{c}}$ and between $\varepsilon_{c c}, \varepsilon_{c}$ are proposed by Mander et al. [17] and Hu et al. [10] as follows (Figure 8(a)). 


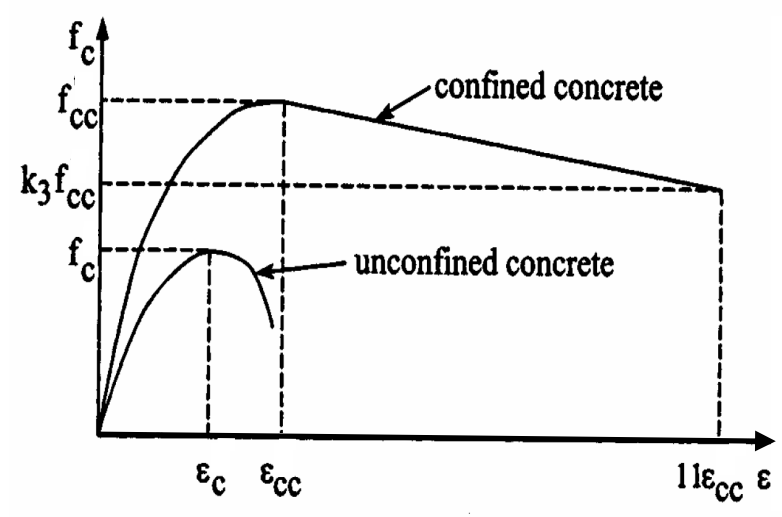

(a) Sketch

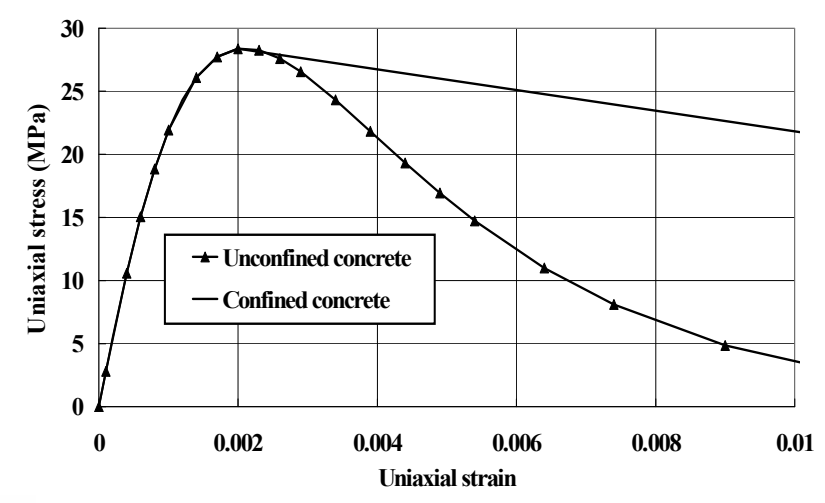

(b) Input Curve

Figure 8. Uniaxial Stress Versus Strain Relations for Concrete

$$
\begin{aligned}
& f_{c c}=f_{c}+k_{1} f_{l} \\
& \begin{aligned}
\varepsilon_{c c} & =\varepsilon_{c}\left(1+k_{2} \frac{f_{l}}{f_{c}}\right) \\
f_{l} / \sigma_{y} & =0.055048-0.001885(b / t) \\
& =0.0
\end{aligned}
\end{aligned}
$$$$
(29.2 \leq b / t \leq 150)
$$

Here, $f_{l}$ represents the confining pressure around the concrete core. $k_{1}$ and $k_{2}$ are constants which were set as 4.1 and 20.5 based on the study of Richart et al. [18]. $b$ denotes the flange width and $t$ is the flange thickness. When the strain is larger than peak strain $\varepsilon_{c c}$, a linear descending line is used to model the softening behavior of concrete. The strength degradation parameter corresponding to $11 \varepsilon_{c c}$ for CFT columns with box-section is calculated as follows.

$$
\begin{aligned}
k_{3} & =0.000178(b / t)^{2}-0.02492(b / t)+1.2722 & & (17 \leq b / t \leq 70) \\
& =0.4 & & (70 \leq b / t \leq 150)
\end{aligned}
$$

According to the above formula, the uniaxial stress- strain curve of confined concrete is shown in Figure 8(b). Because the value of $b / t$ of Specimen U12-C is 58.3 (Here, flange width $b=263 \mathrm{~mm}$; plate thickness $t=4.51 \mathrm{~mm}$ ), the peak stress of confined concrete has the same value as that of unconfined concrete. The main difference between confined concrete and unconfined concrete lies in that the stress deterioration slope of confined concrete is much larger than that of unconfined concrete, as stated in Eqn. 4 and Figure 8(b).

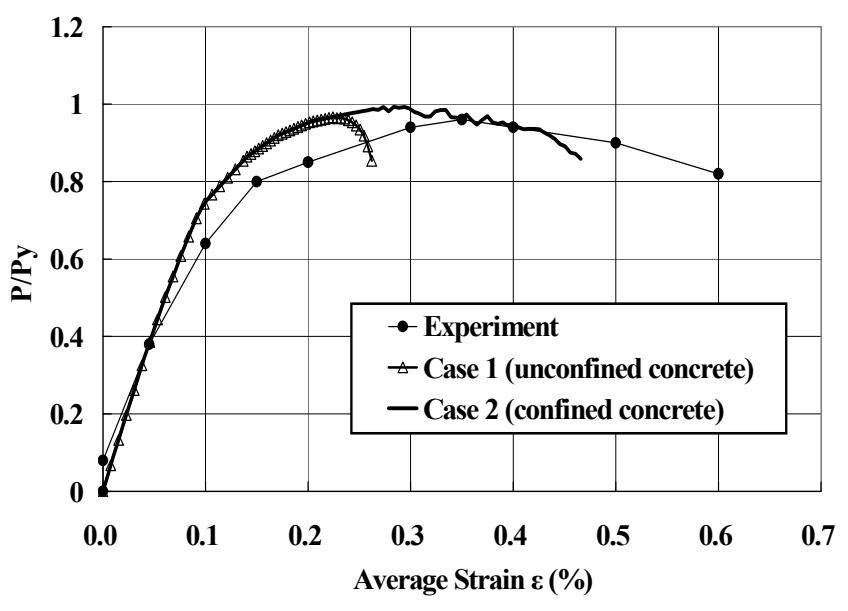

Figure 9. Computed Load-average Strain Curves of Concrete-filled Steel Column under Compression 


\subsection{Analytical Results}

The analytical results of nondimensionized axial load, $P / P_{y}$, versus average strain are shown in Figure 9. Here, $P_{\mathrm{y}}$ is the squash load of concrete-filled columns (Ge and Usami [2]). It is observed

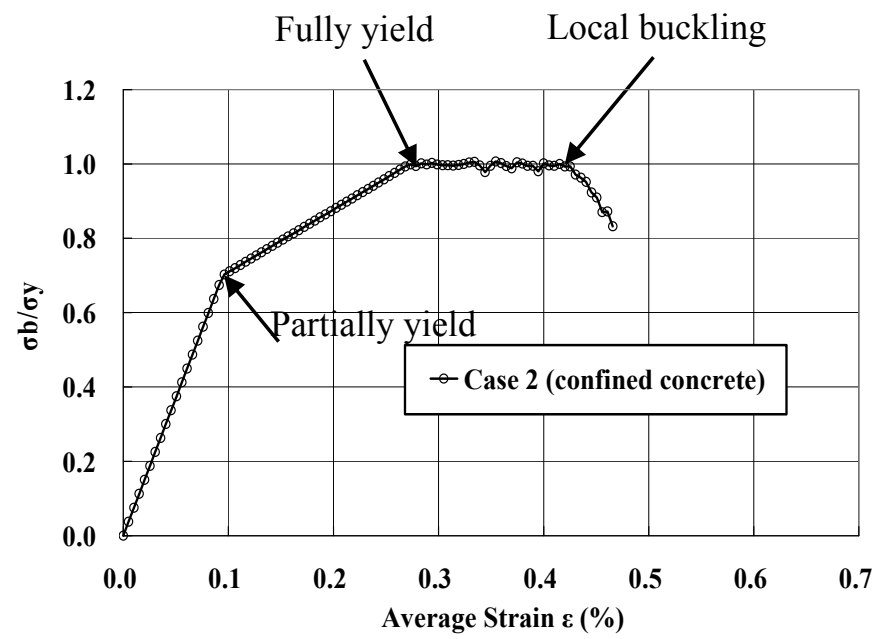

(a) Steel

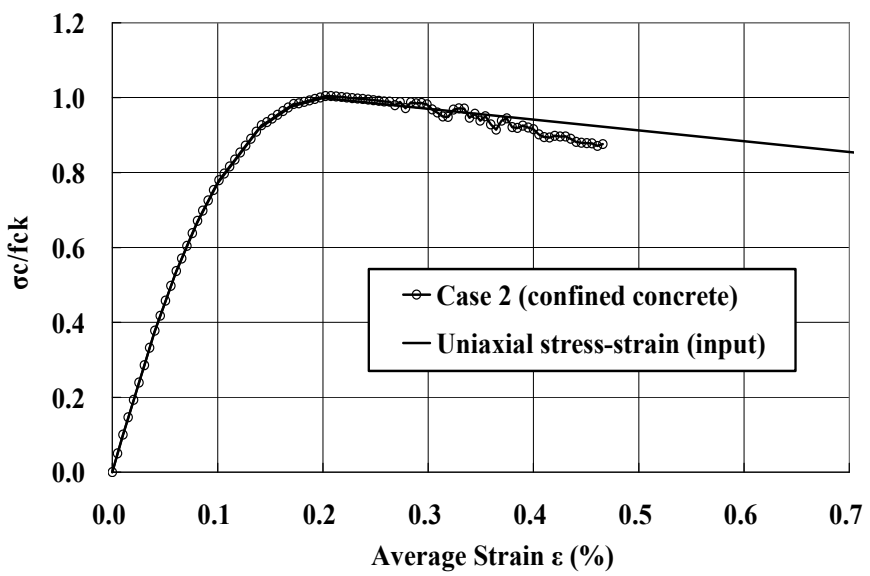

(b) Concrete

Figure 10. Computed Average Stress -Average Strain Curves of Steel and Concrete member

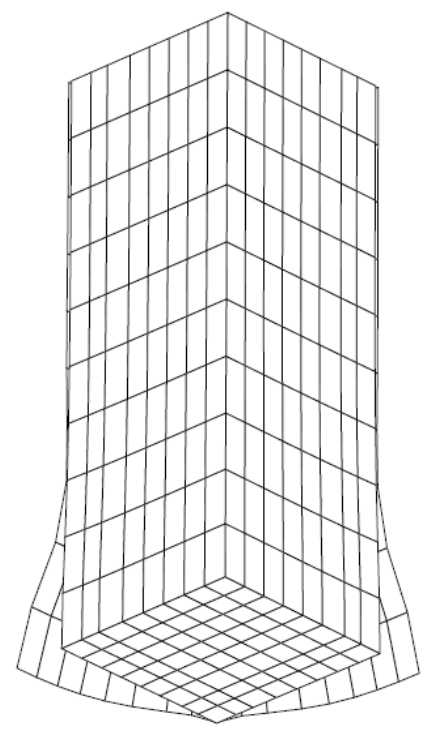

(a) Elevation View

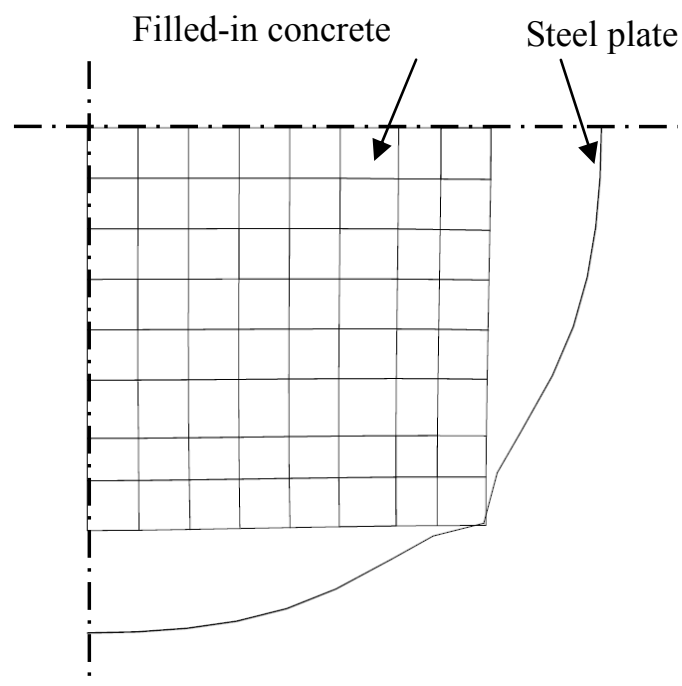

(b) Plane View

Figure 11. Local Buckling Mode of Case 2 at Final Step (Opening of Interface Element)

that both the analyses of Case 1 and Case 2 well predict the ultimate strength of the experiment. However, the post-peak strength decreases rapidly in the analysis of Case 1. On the contrary, the analytical result of Case 2 shows a gentle strength deterioration behavior at post-peak stage, which coincides well with the experimental result. Comparisons of computed load-average strain curves between Case 1 and Case 2 indicate that the lateral confinement pressure of steel plate have a large influence on the post-peak behavior of the concrete-filled steel column.

Figure 10 shows the computed average stress-average strain curves of steel and concrete members, respectively. Figure 10(a) clearly illustrates 3 stages of the steel members, that is, partially yield stage, fully yield stage, and finally the stage of local buckling. It is noted that partially yield stage appears only when the residual stresses are accounted for in the analysis. The local buckling 
mode of Case 2 at final step is shown in Figure 11 (Deformation scale is 3.0). It is observed that local buckling arises at the mid-span of the compressed column.

\section{BENDING BEHAVIOR OF PARTIALLY CONCRETE-FILLED STEEL COLUMN}

\subsection{Analytical Model}

The analytical model of a concrete-filled steel column with box shape UC70-25-3[0] (Ge et al. [4]; Ge and Usami [3]) is shown in Figure 12. Due to its symmetry, half of the column is modeled. The same element types as those stated in previous section are employed to model the concrete part (solid element), steel part (shell element), as well as the interaction behavior between steel and concrete (interface element). Moreover, the filled-in concrete is also possible to detach from the base plate and diaphragm. Nonlinear interface elements are set up between the concrete and base plate, diaphragm.

\subsection{Geometrical and Material Properties}

The main geometrical properties of this specimen are: $R_{f}=0.75, \bar{\lambda}=0.276$, flange width $B=738 \mathrm{~mm}$, web width $D=157 \mathrm{~mm}$, flange and web thickness $t=5.87 \mathrm{~mm}$, column length $h=788 \mathrm{~mm}$, length of filled-in concrete from the base $l_{c}=236 \mathrm{~mm}$. The uniaxial stress-strain relations for steel (see Figure 7) and confined concrete (see

Figure 8(b)) are adopted, with the following material properties: $\sigma_{y}=308 \mathrm{MPa}$; $E=211 \mathrm{GPa} ; v=0.27$, $E_{\mathrm{st}}=5.83 \mathrm{GPa}$, and $\varepsilon_{s t}=2.01 \%$ for steel, $f_{c}=$ $36.4 \mathrm{MPa} ; E=24.2 \mathrm{GPa}$; $v=0.158$ for concrete. Moreover, the applied axial load ratio $P / P_{y}$ is 0.20 .

As given in Table 1, three cases are considered in the

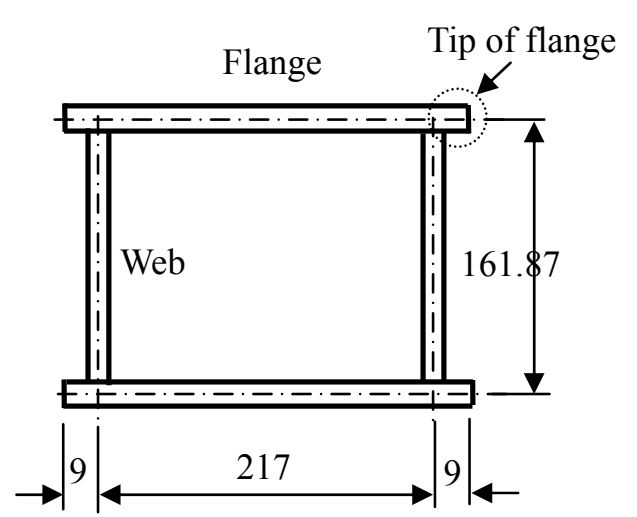

(a) Cross Section

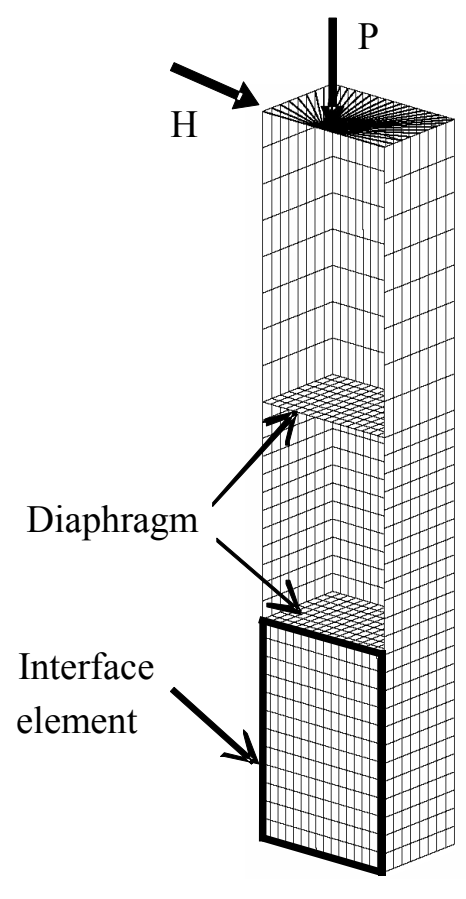

(b) Analytical Model

Figure 12. Analytical Model of Partially Concrete-filled Specimen UC70-25-3[0] under Combined Compression and Bending analysis. The steel column without filled-in concrete is analyzed in Case 1. The difference between Case 2 and Case 3 is the material behavior of interface element. The interface element in Case 2 can only resist compressive stress. The interface element will open (that is to say, the stress becomes zero) as soon as tensile stress arises. The elastic compressive and tension behavior of the interface element is assumed in Case 3. 
Table 1. Analytical Cases

\begin{tabular}{|l|l|l|}
\hline Case No. & Interface Behavior & Remarks \\
\hline Case 1 & - & Only steel part is considered. \\
\hline Case 2 & $\begin{array}{l}\text { Only compressive stresses can be } \\
\text { transferred in the interface element }\end{array}$ & - \\
\hline Case 3 & $\begin{array}{l}\text { Both compressive and tensile stresses can } \\
\text { be transferred in the interface element }\end{array}$ & - \\
\hline
\end{tabular}

\subsection{Analytical Results}

Comparison of nondimensionalized horizontal load versus horizontal displacement relation is shown in Figure 13. It is observed that Case 1 reaches peak load $\left(H / H_{y}=1.06\right)$ at $\delta / \delta y=1.9$. The local buckling occurred at the column base, as shown in Figure 14(a). Compared with Case 1, Case 2 predicts a higher ultimate strength of $H / H_{y}=1.45$. Due to the existence of concrete, the inward local buckling at the column base is prevented at Case 2. The flange plate above the concrete-filled part deforms inwards (see Figure 14(b)). The ultimate strength predicted by Case 2 coincides well with the experiment. However, Case 2 diverges at the moment when the analysis enters the post-peak regime. The divergence reason is due to the lateral detachment of steel part from concrete part, as shown in Figure 14(c).

Case 3 successfully predicts both the ultimate strength and post-peak behavior although the predicted post-peak strength is a little lower than that of the experiment. The possible reason is due to the simplification of the assumed elastic compressive and tension behavior in modeling the interface element. The buckling mode of Case 3 coincides well with the experiment (see Figure 15). The local buckling occurs at the position just above the concrete-filled part. Comparison of Case 2 with Case 3 demonstrates that the material property of interface

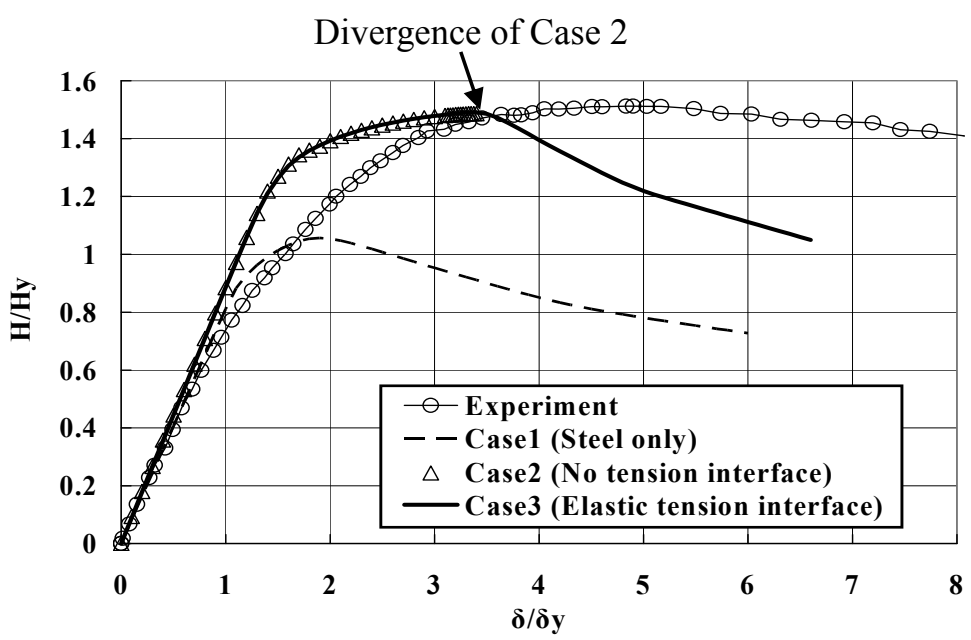

Figure 13. Comparison of Load-displacement Relation of Partially Concrete-filled Specimen UC70-25-3[0] under Combined Compression and Bending element is a key point in predicting the post-peak behavior of concrete filled-in steel column. Further research is needed to focus on the evaluation of tensile stress that the interface element can really resist.

\section{CONCLUSIONS}

This paper addresses an elasto-plastic large deformation formulation of hollow and concrete-filled steel columns. Based on the analytical results, the following conclusions can be drawn.

1. The predicted hysteretic curve and buckling mode of steel structures such as the pipe specimen P1 and box specimen KD-5 coincide well with the experimental results. 
2. The present analysis gives accurate predictions to the ultimate strength of concrete-filled steel structures. The lateral confinement pressure can not be neglected in predicting the post-peak behavior of axial compressed concrete filled-in steel column.

3. The interaction treatment between the steel and concrete is very important in predicting the post-buckling behavior of partially concrete filled-in steel column subjected to combined compression and bending.
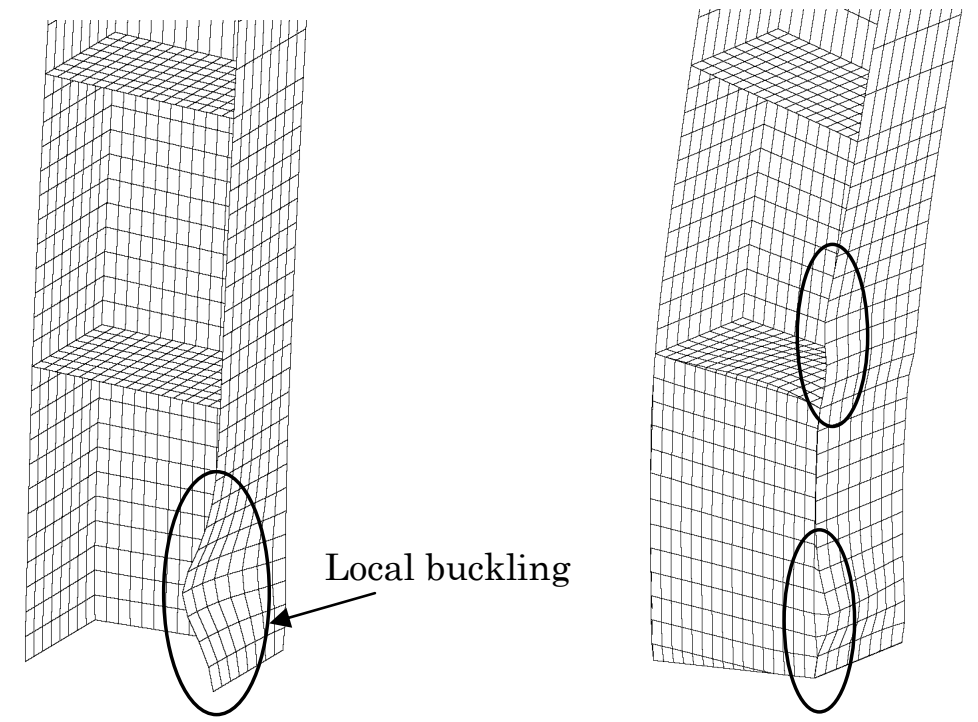

(b) Total Deformation of Case 2 Deformation Mode of Partially Concrete-filled
under Combined Compression and Bending

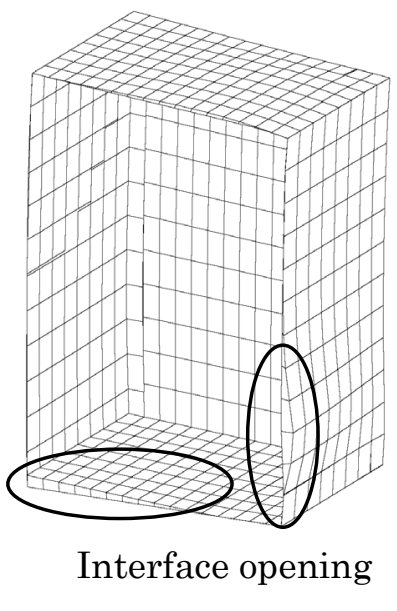

(c) Interface Opening of Case 2

Figure 14. Comparison of Deformation Mode of Partially Concrete-filled Specimen UC70-25-3[0]

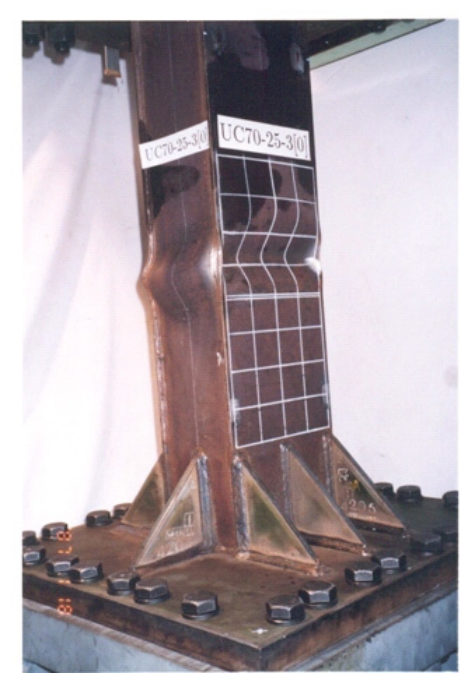

(a) Experiment

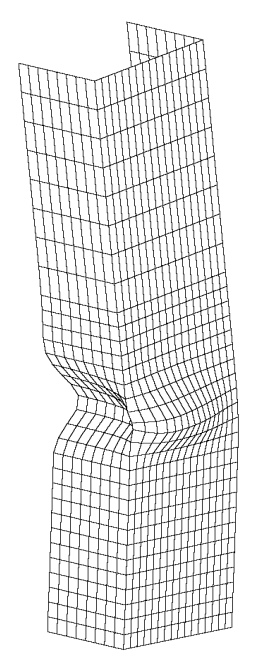

(b) Analysis

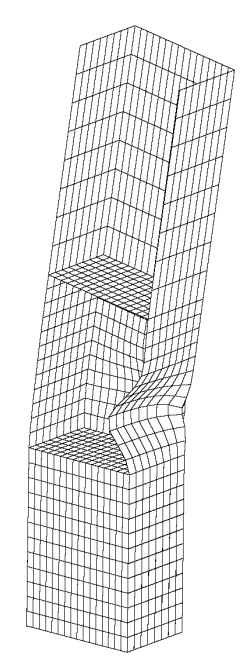

Experiment and Case 3

Further researches are needed to focus on the evaluation of tensile stress that the interface element can really resist, as well as a series of parametric studies to evaluate the ultimate strength and ductility behavior of such concrete filled-in steel columns. 


\section{REFERENCES}

[1] Gao, S.B., Usami, T. and Ge, H.B., "Ductility Evaluation of Steel Bridge Piers with Pipe-sections", Journal of Engineering Mechanics, ASCE, 1998, Vol. 124, No. 3, pp. 260-267.

[2] Ge, H.B. and Usami, T., "Strength Analysis of Concrete-filled Thin-walled Steel Box Columns", Journal of Construction Steel Research, 1994, Vol. 30, pp. 259-281.

[3] Ge, H.B. and Usami, T., "Cyclic Tests of Concrete-filled Steel Box Columns", Journal of Structural Engineering, ASCE, 1996, Vol. 122, No. 10, pp. 1169-1177.

[4] Ge, H.B., Usami, T. and Toya, K., "A Study on Strength and Deformation Capacity of Concrete-filled Steel Columns under Cyclic Loading", Journal of Structural Engineering, JSCE, 1994, 40A, pp.163-176. (in Japanese)

[5] Ge, H.B., Gao, S.B. and Usami, T., "Stiffened Steel Box Columns. Part 1: Cyclic Behavior", Earthquake Engineering and Structural Dynamics, 2000, Vol. 29, pp. 1691-1706.

[6] Morino, S., "Recent Developments in Hybrid Structures in Japan-Research, Design, and Construction", Engineering Structures, 1998, Vol. 20, No. 4-6, pp. 336-346.

[7] Schneider, S.P., "Axial Loaded Concrete-filled Steel Tubes", Journal of Structural Engineering, ASCE, 1998, Vol. 124, No. 10, pp. 1125-1138.

[8] Susantha, K.A.S., Ge, H.B. and Usami, T., "A Capacity Prediction Procedure for Concrete-filled Steel Columns", Journal of Earthquake Engineering, 2001, Vol. 5, No. 4, pp.483-520.

[9] Susantha, K.A.S., Ge, H.B. and Usami, T., "Cyclic Analysis and Capacity Prediction of Concrete-filled Steel Box Columns", Earthquake Engineering and Structural Dynamics, 2002, Vol. 31, pp. 195-216.

[10] Hu, H.T., Huang, C.S., Wu, M.H. and Wu, Y.M., "Nonlinear Analysis of Axially Loaded Concrete-filled Tube Columns with Confinement Effect", Journal of Structural Engineering, ASCE, 2003, Vol. 129, No. 10, pp.1322-1329.

[11] DIANA User's Manual. Ver. 9.1, 2005.

[12] Nakamura, S., Yasunami, H., Kobayashi, Y., Nakagawa, T. and Mizutani, S., “An Experimental Study on the Seismic Performance of Steel Bridge Piers with Less Stiffened and Compact Sized Section", Proceeding of Nonlinear Numerical Analysis and Seismic Design of Steel Bridge Piers, JSCE, 1997, pp. 331-338.

[13] Nishikawa, K., Yamamoto, S., Natori, T., Terao, O., Yasunami, H. and Terada, M., "An Experimental Study on Improvement of Seismic Performance of Existing Steel Bridge Piers”, Journal of Structural Engineering, JSCE, 1996, Vol. 42A, pp. 975-986. (in Japanese)

[14] Chen, W.F. and Ross, D.A., "Test of Fabricated Tubular Columns", Journal of Structural Division, ASCE, 1977, Vol. 103(ST3), pp. 619-634.

[15] Usami, T. and Ge, H.B., "Cyclic Behavior of Thin-walled Steel Structures-Numerical Analysis", Thin Walled Structures, 1998, Vol. 32, No. 1/3, pp. 41-80.

[16] Japan Concrete Standard Specification. Aseismic Performance Verification Part, 2002. (in Japanese)

[17] Mander, J.B., Priestley, M.J.N. and Park, R., "Theoretically Stress-strain Model for Confined Concrete", Journal of Structural Engineering, ASCE, 1988, Vol. 114, No. 8, pp.1804-1826.

[18] Richart, F.E., Brandtzaeg, A. and Brown, R.L., "A Study of the Failure of Concrete under Combined Compressive Stresses", Bulletin 185, University of Illinois Engineering Experimental Station, Champaign, III, 1928. 
